\title{
Efeito da qualidade de luz no desenvolvimento da moringa sob telados de diferentes cores em clima semiárido
}

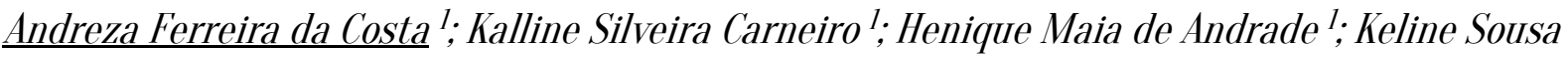 \\ Albuquerque Uchoa ${ }^{l}$
}

andreza121.af@gmail.com

1. Instituto Federal de Educação, Ciência e Tecnologia do Ceará (IFCE), Campus Limoeiro do Norte - CE.

Histórico do Artigo:

Recebido em: 04 de janeiro de 2019

Aceito em: 22 de julho de 2019

Publicado em: 30 de agosto de 2019

Resumo: A moringa originária da Ásia é conhecida no mundo por ser utilizada por diversas indústrias: alimentícia, cosmética, dentre outras. É uma planta de crescimento rápido e alta adaptabilidade a diversos climas. 0 trabalho tem o objetivo de avaliar o efeito dos telados no comportamento inicial do desenvolvimento da moringa, sob o uso de telados de diferentes colorações. 0 experimento foi realizado no Instituto Federal de Educação, Ciência e tecnologia (IFCE), em Limoeiro do Norte-CE. 0 delineamento experimental foi inteiramente casualizado, constituído por cinco tratamentos com oito repetições, (TI-Telado cinza, TII-telado vermelho, TIII-telado verde, TIV-telado preto, TV-sem telado). Foi avaliado o IVE (Índice de Velocidade de Emergência), altura da planta (cm), diâmetro do caule $(\mathrm{cm})$, massa seca da parte aérea e radicular $(\mathrm{g})$, açúcares solúveis totais (\%) e Proteína Bruta (\%). 0s dados foram submetidos à análise de variância, seguido de teste de média (Tukey) por meio do programa ASSISTAT. No IVE, massa seca das raízes e proteína bruta, não houve diferença estatística significativa entre os tratamentos. Na altura das plantas, os telados obtiveram médias superiores comparadas a testemunha (sem telado). Em relação ao diâmetro do caule, o TV apresentou redução significativa comparando-o aos demais tratamentos. Entretanto, para a matéria seca da parte aérea e na concentração de açúcares solúveis totais, o TV se sobressaiu significativamente dos demais tratamentos, obtendo valores superiores. Assim, observou-se que os telados promoveram apenas o alongamento celular, porém não ocorreu a incorporação de matéria seca.

Palavras-chave: Cultivo protegido, Fisiologia, Fotomorfogênese, Moringa oleifera.

\section{Effect of light quality in the development of moringa under ties of different colors in semiarid climate}

\begin{abstract}
The moringa originating in Asia is known in the world for being used by several industries: food, cosmetics, among others. It is a plant of fast growth and high adaptability to diverse climates. The objective of this work is to evaluate the effect of the screenings on the initial development behavior of the moringa, under the use of different stains. The experiment was carried out at the Federal Institute of Education, Science and Technology (IFCE), in Limoeiro do Norte-CE. The experimental design was completely randomized, consisting of five treatments with eight replicates (TI-Gray roof, TII-red screen, TIII-green screen, TIV-black screen, TV-without screen). Plant height $(\mathrm{cm})$, stem diameter $(\mathrm{cm})$, dry mass of shoots and roots $(\mathrm{g})$, total soluble sugars $(\%)$ and crude protein $(\%)$ were evaluated. Data were submitted to analysis of variance, followed by Tukey test using the ASSISTAT program. In IVE, dry mass of roots and crude protein, there was no significant statistical difference between treatments. At plant height, the weeds obtained higher means compared to the control (without weaving). Regarding the diameter of the stem, the TV showed a significant reduction comparing it to the other treatments. However, for the dry matter of the aerial part and in the concentration of total soluble sugars, the TV stood out significantly of the other treatments, obtaining higher values. Thus, it was observed that the screenings promoted only the cellular elongation but did not occur the incorporation of matter dry.
\end{abstract}

Keywords: Protected crop, Physiology, Photomorphogenesis, Moringa oleifera. 


\section{Efecto de la calidad de la luz en el desarrollo de la moringa bajo lazos de diferentes colores en el clima semiarido}

Resumen: La moringa originaria de Asia es conocida en el mundo por ser utilizada por varias industrias: alimentos, cosméticos, entre otras. Es una planta de rápido crecimiento y alta adaptabilidad a diversos climas. El objetivo de este trabajo es evaluar el efecto de los exámenes de detección en el comportamiento de desarrollo inicial de la moringa, bajo el uso de diferentes manchas. El experimento se llevó a cabo en el Instituto Federal de Educación, Ciencia y Tecnología (IFCE), en Limoeiro do Norte-CE. El diseño experimental fue completamente al azar, y consistió en cinco tratamientos con ocho réplicas (techo TI-Grey, pantalla TII-red, pantalla TIII-verde, pantalla TIV-negro, TV-sin pantalla). Se evaluaron la altura de la planta $(\mathrm{cm})$, el diámetro del tallo $(\mathrm{cm})$, la masa seca de los brotes y las raíces (g), los azúcares solubles totales (\%) y la proteína bruta (\%). Los datos se enviaron al análisis de varianza, seguido de la prueba de Tukey con el programa ASSISTAT. En IVE, masa seca de raíces y proteína cruda, no hubo diferencia estadística significativa entre los tratamientos. A la altura de la planta, las malezas obtuvieron medias más altas en comparación con el control (sin tejer). Con respecto al diámetro del vástago, el televisor mostró una reducción significativa en comparación con los otros tratamientos. Sin embargo, para la materia seca de la parte aérea y en la concentración de azúcares solubles totales, el televisor se destacó significativamente de los otros tratamientos, obteniendo valores más altos. Por lo tanto, se observó que las pruebas de detección promovieron solo el alargamiento celular, pero no se produjo la incorporación de materia Seco.

Palabras clave: Cultivo protegido, Fisiología, Fotomorfogénesis, Moringa oleifera.

\section{INTRODUÇ̃̃o}

A Moringa Oleifera, planta originária do continente asiático, pertence à família Moringaceae, característica de angiospermas perenes, que inclui 12 outras espécies. É cultivada em áreas tropicais por todo o mundo, sendo conhecida por vários nomes populares: árvore de baqueta, árvore de rábano e malunggay, sendo este último o mais encontrado na literatura (ROLIM, 2016).

Essa espécie pode gerar vários benefícios para os países que a cultiva, pois dentre os seus inúmeros usos, contém alto teor proteico e, devido às suas características, pode ser utilizada por diversas indústrias, sendo elas alimentícia, medicinal, de biodiesel, cosmética, dentre outras (ALMEIDA, 2017). A sua semente pode ser utilizada em sistemas de tratamento de água devido a sua característica de floculante natural (OLIVEIRA, 2018).

0 cultivo de espécies vegetais praticada em regiões semiáridas, como no Nordeste brasileiro, é muito variada. Isso ocorre devido a alguns fatores que frequentemente são apontados como entraves ao desenvolvimento da agricultura nordestina, incluindo as questões ambientais (CASTR0, 2012). Dos elementos que caracterizam o clima, a radiação solar, a temperatura e a umidade relativa do ar são aqueles que exercem maior efeito sobre o desenvolvimento de plantas (SILVA et al., 2010). 
Efeito da qualidade de luz no desenvolvimento da moringa sob telados de diferentes cores em clima semiárido

A maioria das plantas reagem de maneiras diferentes de acordo com a qualidade da luz, refletindo no seu crescimento e desenvolvimento conforme o ambiente em que está sendo submetida. Essas particularidades tornam-se importantes ferramentas de estudo, especialmente em condições controladas, na busca de otimização do cultivo (COSTA et al. 2010).

Segundo Saraiva (2013), alguns trabalhos demostram a capacidade de algumas espécies arbóreas responderem de formas diferentes quando expostas ao espectro de luz, ressaltando a importância de estudos voltados à utilização de telados, para obtenção de uma melhor produção e sucesso no plantio de mudas.

0 uso de telas coloridas, que influencia na qualidade da radiação, pode interferir no crescimento e o desenvolvimento, assim como associada à espécie vegetal, cultivar e condições de cultivo (HIRATA, 2014). Isso ocorre devido os telados conseguirem amenizar a ação dos raios solares e dessa forma torna-se uma possibilidade de estudo e avaliação do desenvolvimento das culturas nessas condições (AHEMD et al.,2016).

As telas coloridas, como as telas de coloração azul ou vermelha, agem sobre alguns vegetais como as olerícolas, plantas ornamentais e etc, modificando o espectro de luz e consequentemente melhorando o desempenho da planta, visto que ocorre alterações quanto a intensidade, a qualidade e a quantidade de luz que chegam as plantas, variando de acordo com a cultura e a cor da tela utilizada (FIGUEIRED0 \& LEITE, 2011).

Com isso, o objetivo foi avaliar o efeito dos telados de diferentes cores no comportamento inicial do desenvolvimento da moringa.

\section{MATERIAL E MÉTODOS}

A pesquisa foi conduzida no Instituto Federal de Educação, Ciência e Tecnologia do Ceará (IFCE) do município de Limoeiro do Norte - CE. A região é característica do clima tipo BSw'h' (semiárido, com máximo de chuvas no outono e muito quente), temperatura média anual de 28,5 $\mathrm{C}$, com umidade média relativa do ar de 62\% (DNOCS, 2015).

0 experimento foi implantado no início de fevereiro de 2017. Foram utilizadas sementes de uma planta existente no próprio campus, devido a disponibilidade e a facilidade na coleta. As sementes não foram submetidas a nenhum tipo de tratamento para quebra de dormência, sendo semeadas de forma direta em vasos plásticos de 5 litros com substrato formado pela mistura de composto orgânico e areia na proporção de 1:1. 
Os vasos foram acondicionados em estruturas de ferro de formato retangular com dimensões de $80 x 100 \mathrm{~cm}$. Cada estrutura foi totalmente coberta com um telado de cor diferente das demais. A irrigação foi feita manualmente de forma homogênea e de acordo com a necessidade da cultura, no qual foi estabelecido uma irrigação por dia, sendo disponibilizando 1000ml para cada planta, no intuito manter o grau de umidade à capacidade de campo.

0 delineamento experimental utilizado foi inteiramente casualizado (DIC), composto por cinco tratamentos (TI - Telado Cinza, TII - Telado Vermelho, TIII - Telado Verde, TIV - Telado Preto, TV - Sem telado (testemunha), com oito repetições para cada tratamento, totalizando 40 amostras.

Inicialmente foi avaliado o Índice de Velocidade de Emergência (IVE), em que foram realizadas contagens diárias das plântulas durante oito dias, iniciando a partir do quarto dia após a semeadura. A fórmula utilizada foi proposta pela metodologia de Maguire (1962), então:

$$
I V E=(G 1 / N 1)+(G 2 / N 2)+\ldots+(G n / N n)
$$

IVE = Índice de Velocidade de Emergência;

G = número de plântulas computadas em cada contagem

$\mathrm{N}$ = número de dias após a semeadura: $4,5, \ldots, 11$ dias.

Após dezessete dias da semeadura, quando a emergência das plantas já estava estabelecida, iniciaram-se as avaliações de crescimento não destrutivas, no qual não é necessário a destruição da planta para obter os resultados, sendo analisada a altura da planta e o diâmetro do caule, com o auxílio de fita métrica. Essas avaliações foram realizadas durante os meses de fevereiro e março com o intervalo de 15 dias entre as avaliações.

Com 120 dias após semeadura foram realizadas as avaliações de crescimento destrutivas, em que se fez a aferição do peso da massa seca de todas as partes da planta, no qual foi dividido em parte aérea e sistema radicular, sendo pesados separadamente. As amostras foram lavadas e posteriormente colocadas em sacos de papel em uma estufa a $65^{\circ} \mathrm{C}$ com circulação de ar durante 72 horas e após esse intervalo obteve-se os valores de massa seca (g).

A análise de açúcares solúveis totais foi realizada através da metodologia descrita por Yemn (1954), sendo a leitura em absorbância no espectrofotômetro a 620mm.

A análise de concentração de nitrogênio das folhas, foi descrita pela metodologia de Malavolta et al. (1989) e Silva (2009). 0 resultado encontrado foi convertido para proteína bruta, 
Efeito da qualidade de luz no desenvolvimento da moringa sob telados de diferentes cores em clima semiárido

multiplicando-0 por 6,25, pelo fato de ser considerado que o nitrogênio representa uma média de 16\% da constituição das proteínas.

Todas as avaliações de crescimento, sendo elas destrutivas ou não destrutivas, foram realizadas nas oito repetições de cada tratamento.

Os dados foram submetidos à análise de variância, seguido de teste de média (Tukey) a 5\% de probabilidade, por meio do programa ASSISTAT (UFCG) versão 7.7 beta.

\section{RESULTADOS E DISCUSSÃ0}

No IVE (gráfico 1), os tratamentos não obtiveram diferença estatística significativa (p.< 0,05). Porém, em termos numéricos o telado vermelho apresentou melhor resultado em comparação aos demais. 0 tratamento TV que obteve o menor resultado. Isso mostra que os telados interferem positivamente na velocidade de emergência das sementes, apesar de não apresentarem diferença estatística significativa no referido trabalho.

Gráfico 1 - Índice de velocidade de emergência (IVE).

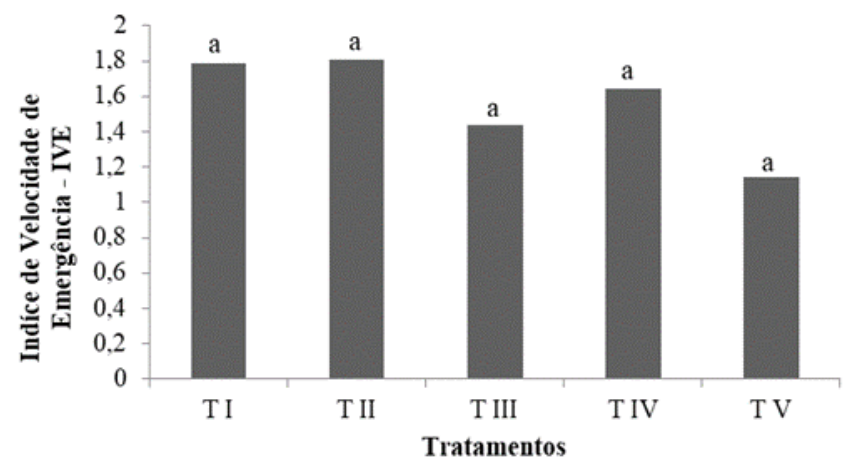

Fonte: Pesquisa de campo (2017).

0s resultados obtidos ficaram abaixo dos resultados encontrados por Agustini et al. (2017) que mostrou o IVE das sementes de moringa em pleno sol, com uma média de 2,44.

A velocidade de emergência das sementes é um índice importante a ser avaliado, pois através dessa avaliação verifica-se a característica que a espécie demostra quanto a estratégia de se estabelecer em um determinado ambiente o mais rápido possível, aproveitando as condições ambientais favoráveis a germinação (MEL0 JÚNIOR et al., 2018). Por esse motivo, é importante a utilização de técnicas que promovam um aceleramento na emergência das plantas, visto que é um fator que otimiza o tempo para o estabelecimento da cultura. 
Na altura da planta (tabela 1), houve diferença estatística significativa entre a testemunha, que apresentou menores resultados em todas as avaliações, e os demais tratamentos. Na terceira avaliação, especificamente, o tratamento com telado preto (TIV) se destacou dos outros tratamentos. Com isso, observa-se que os telados de modo geral promoveram o maior crescimento das plantas, porém o telado preto foi o que se sobreesaiu dentre os telados testados para essa variável.

Tabela 1 - Altura da planta (cm).

\begin{tabular}{|cccccc|}
\hline & $\mathbf{1}^{\mathbf{0}}$ Avaliação & $2^{\mathbf{0}}$ Avaliação & $3^{\mathbf{0}}$ Avaliação & $4^{\mathbf{0}}$ Avaliação & $5^{\mathbf{0}}$ Avaliação \\
\hline TI & 19,8000 a & 42,3000 a & $64,2750 \mathrm{~b}$ & 88,4375 a & 103,6750 a \\
\hline TII & 20,1375 a & 44,5375 a & $66,0250 \mathrm{ab}$ & 90,0875 a & 105,8000 a \\
\hline TIII & 20,3375 a & 44,4625 a & 67,3875 ab & 91,1250 a & 104,1625 a \\
\hline TIV & 21,4875 a & 46,1250 a & 70,6875 a & 94,7750 a & 105,0875 a \\
\hline TV & 11,7625 b & $22,4750 \mathrm{~b}$ & 33,5625 c & $55,9250 \mathrm{~b}$ & 70,1375 b \\
\hline CV\% & 10,80 & 10,13 & 6,90 & 6,78 & 7,07
\end{tabular}

Médias seguidas de mesma letra minúscula, na coluna, não diferem entre si, pelo teste de Tukey, a 5\% de probabilidade.

Fonte: Pesquisa de campo (2017)

Corroborando com a presente trabalho, Henrique et al. (2011) em seu experimento com mudas de café cultivadas sob o uso de tela de diferentes colorações, mostrou que as alturas das plantas foram influenciadas pelas telas de coloração vermelha, seguidas de preta e azul, onde as mesmas proporcionaram os maiores incrementos na altura da planta, apresentando resultados semelhantes ao referido trabalho.

Almeida (2016) avaliando o desenvolvimento da cultura do lisianthus (Eustoma grandiflorum) em Piracicaba-SP, utilizando as malhas com diferentes cores, também observou que a malha de coloração vermelha proporcionou uma maior altura de haste das plantas. Assim como Calaboni (2014) e Sampaio (2018), que também ressaltaram o mesmo comportamento no cultivo duas espécies de heliconeas e de plantas de Costus lasius Loes, respectivamente.

Esses resultados comparados com o presente trabalho mostram que no momento da escolha de telado colorido, deve-se levar em consideração a cultura que será cultivada, pois as 
Efeito da qualidade de luz no desenvolvimento da moringa sob telados de diferentes cores em clima semiárido

espécies vegetais podem apresentar inumeras variações em seu comportamento quando submetidos a esse tipo de técnica.

Para diâmetro do caule (tabela 2), a testemunha também obteve resultados inferiores aos demais tratamentos. Na primeira avaliação os tratamentos TII, TIII e TIV não diferenciaramse estatisticamente, apresentando melhores resultados, seguidos do TI e TV. Já nas demais avaliações, numericamente, o tratamento II (telado vermelho), sobresaiu-se dos demais tratamentos, obtendo os maiores valores.

Tabela 2 - Diâmetro do caule (cm).

\begin{tabular}{|c|c|c|c|c|c|}
\hline & $1^{0}$ Avaliação & $2^{0}$ Avaliação & $3^{0}$ Avaliação & $4^{0}$ Avaliação & $5^{0}$ Avaliação \\
\hline TI & $1,0125 \mathrm{ab}$ & 2,2875 a & 3,5375 a & 5,0250 a & 5,6625 a \\
\hline TII & 1,1250 a & 2,3625 a & 3,6625 a & 5,2875 a & 5,7625 a \\
\hline TIII & 1,0875 a & 2,2875 a & 3,5625 a & 4,9625 a & 5,3125 a \\
\hline TIV & 1,0625 a & 2,1750 a & 3,5875 a & 4,9875 a & 5,2500 a \\
\hline TV & $0,8250 \mathrm{~b}$ & $1,7000 \mathrm{~b}$ & $2,4125 \mathrm{~b}$ & 3,2875 b & $4,0375 \mathrm{~b}$ \\
\hline CV\% & 14,47 & 10,04 & 7,12 & 7,44 & 7,19 \\
\hline
\end{tabular}

Médias seguidas de mesma letra minúscula, na coluna, não diferem entre si, pelo teste de Tukey, a $5 \%$ de probabilidade.

Fonte:Pesquisa de campo (2017)

Assim como nos resultados encontrados na moringa, a utilização de telados no crescimento de mudas de ipês, também afetam de diâmetro do coleto e a altura da planta (NASCIMENTO, 2014; SABIN0, 2016). Almeida (2017), reforça a utilização do telado vermelho, recomendando-o para produtores da área de floricultura.

Ao contrário dos ressultados obtidos no referido trabalho, Abreu (2013) avaliando o efeito da qualidade de luz no crescimento de plantas de majericão em ambiente controlado, observou que não ocorre influência das diferentes incidencias de luz no diâmetro das plantas. Dousseau (2017), também observou o mesmo comportamento no crescimento de Flora do Brasil (Tapirira guianensis).

Na massa seca (tabela 3), quanto a parte aérea (folha e caule), a testemunha obteve 0 resultado supeiror aos demais tratamentos e o TIV o menor valor com 16,88g. Já na parte radicular os tratamentos não obtiveram diferenças estatisticas significativas (p>0,05). 
Tabela 3 - Massa seca (g) da parte aérea e radicular.

\begin{tabular}{ccc}
\hline & PARTE AÉREA & PARTE RADICULAR \\
\hline TI & $17,6006 \mathrm{ab}$ & $18.9386 \mathrm{a}$ \\
TII & $17,6603 \mathrm{ab}$ & $16.8278 \mathrm{a}$ \\
TIII & $17,7619 \mathrm{ab}$ & $19.4159 \mathrm{a}$ \\
TIV & $16,8887 \mathrm{~b}$ & $16.2092 \mathrm{a}$ \\
TV & $18,0979 \mathrm{a}$ & $17.2775 \mathrm{a}$ \\
CV \% & 3,99 & 17.75
\end{tabular}

Médias seguidas de mesma letra minúscula, na coluna, não diferem entre si, pelo teste de Tukey, a $5 \%$ de probabilidade.

Fonte: Pesquisa de campo (2017)

Os resultados obtidos por Souza (2014) foram semelhantes ao presente trabalho, em que foi observado as malhas coloridas não influenciaram a biomassa seca total, porém o ambiente pleno proporcionou os melhores resultados. Ribeiro (2015) observou o mesmo comportamento no cultivo de patchouli [Pogostemon cablin (Blanco) Benth] incluindo que o uso de telas afetou negativamente no crescimento das mesma.

Ao contrário dos resultados encontrados no referido trabalho, Costa (2018) observou que o uso de telas de sombra vermelha aumentaram a biomassa de plantas de Butia capitata, tornando-a a tela mais adequada para o cultivo dessa espécie vegetal nas condições da região sul do estado de Minas Gerais.

0 telado poderá ter interferido na intensidade luminosa exigida pela cultura, que ao invés de otimizar a absorção de luz e favorecer o incremento de matéria seca, provocou o efeito contrário. Com isso, os telados influenciaram positivamente no crescimento e negativamente na matéria seca da moringa. Esse acontecimento pode está relacionado com um possível estiolamento das plantas.

Em casos de estiolamento, ocorre uma alocação dos recursos do vegetal para o alongamento mais rápido do caule, buscando uma maior porção de radiação solar, sendo uma resposta do fitocromo quanto à percepção de sombra, em que algumas dessas respostas são mediadas pela giberelina. Em consequência deste alongamento, a uma redução da área foliar e ramificações (TAIZ, 2013). 
Efeito da qualidade de luz no desenvolvimento da moringa sob telados de diferentes cores em clima semiárido

Quanto à proteína bruta (gráfico 2) não houve diferença estatística significativa. Porém em termos numéricos o TII, seguido do TV, obtiveram os resultados superiores aos outros tratamentos.

Gráfico 2 - Porcentagem de Proteína Bruta (\%) da área foliar.

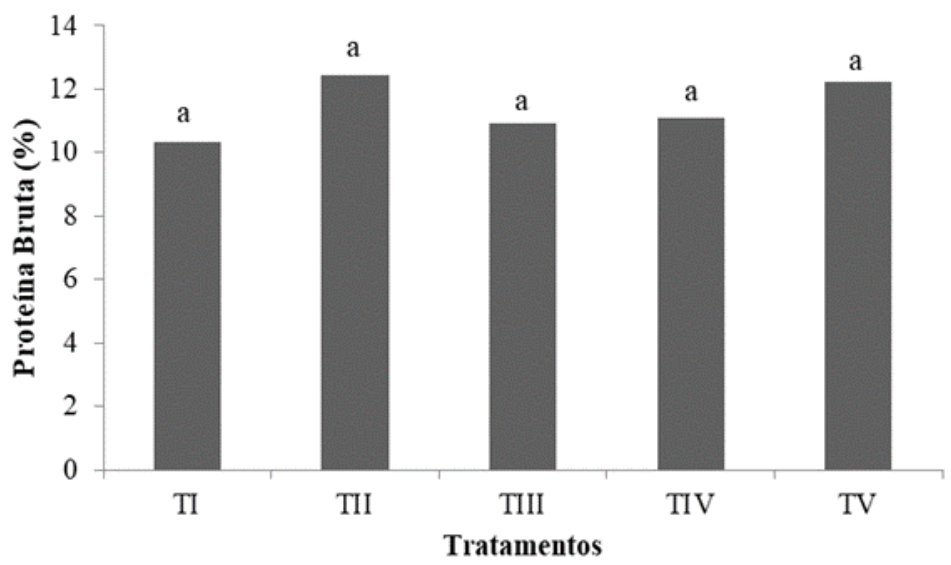

Fonte: Pesquisa de campo (2017)

Com resultados semelhantes aos obtidos no referido trabalho, Vieira (2017) mostrou que no teor de proteína em plantas de ora-pro-nóbis (Pereskia aculeata), a tela vermelha promoveu um resultado inferior comparada aos demais tratamentos e acrescentou que isso pode indicar que a qualidade da luz influencia na produção de proteínas.

Na concentração de açúcares solúveis totais (gráfico 3), o tratamento que melhor sobresaiu-se foi o TV, com uma média de 19,3\% e o tratamento que apresentou menor resultado foi 0 TII com $9,41 \%$.

Gráfico 3 - Açúcares Solúveis Totais (\%).

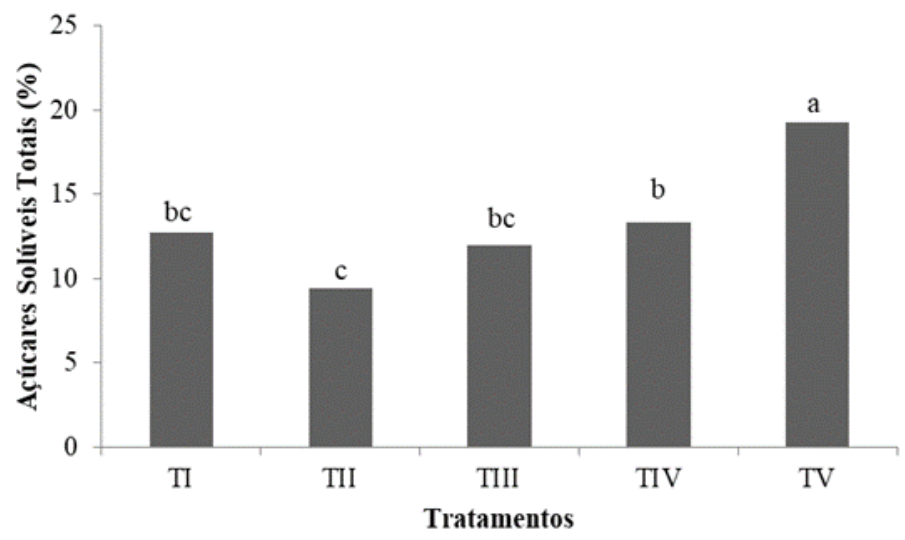

Fonte: Pesquisa em campo (2017) 
Corroborando com esses resultados, Martinazzo (2007), observou uma diferença no acúmulo de açucares, no qual os teores de carboidratos não-estruturais (sacarose, açúcares redutores, carboidratos solúveis totais) nas folhas da espécie vegetal Eugenia uniflora L, mostrou-se maior durante o crescimento das mudas submetidas a cultivo sem o uso de telados.

\section{CONCLUSÃ0}

0 cultivo de moringa sob 0 uso de telados em região semiárida promoveu apenas o alongamento celular, influenciando na altura da planta.

Os telados afetaram negativamente a incorporação de matéria seca e consequentemente reduziu a fitomassa da moringa.

A utilização de telados coloridos pode trazer benefícios no cultivo de plantas. Porém, deve-se considerar que o seu efeito é variado de acordo com a cultura, sendo necessário realizar estudos mais específicos sobre o telado ideal para a espécie vegetal que deseja ser cultivada.

\section{AGRADECIMENTOS}

Ao IFCE - Campus Limoeiro do Norte e a Fundação Cearense de Apoio ao Desenvolvimento Científico e Tecnológico (FUNCAP).

\section{REFERÊNCIAS BIBLIOGRÁFICAS}

ABREU, C. B.; SANTOS, A. R.; SOUZA, G. S.; OLIVEIRA, U. C.; SILVA, J. S. Qualidade de luz no crescimento inicial de plantas de manjericão (0cimum basilicum L.) em ambiente controlado. Enciclopédia biosfera, Goiânia, v.9, n.16, $1855-1862,2013$.

AGUSTINI, M. A. B. et al. Maturidade fisiológica de sementes de Moringa oleifera (Lam). Revista Cultivando o saber, v. 8, n.3, p. 267-278, 2017.

AHEMS, H.A.; AL-FARAJ, A.A.; ABDEL-GHANY, A.M. Shanding greenhouses to improve the microclimate, energy and water saving in hot regiions: A review. Scientia Horticulturae, v. 201, p. 36-45, 2016.

ALMEIDA, C. B. L.; CONDE E SÁ, C.; CARVALHO, R. C. D.; ALMEIDA, L. S.. Estudo prospectivo da moringa na indústria de cosméticos. Cad. Prospec., Salvador, v. 10, n. 4, p. 905-918, 2017.

ALMEIDA, J. M.; CALABONI, C. RODRUGUES P.H.V. Lisianthus cultivation using differentiated light transmission nets. Ornamental Horticulture, v. 22, n.2, p. 143-146, 2016.

ALMEIDA, J.M. Avaliação de três variedade de lisianthus em ambiente protegido com telas de sombreamento de diferentes espectros de cor. 2017. Dissertação (Mestrado em Ciência: Fitotecnia) Piracicaba, São Paulo. 
Efeito da qualidade de luz no desenvolvimento da moringa sob telados de diferentes cores em clima semiárido

CALABONI, C. Utilização de malhas coloridas em cultivo protegido no desenvolvimento de duas espécies de helicônias em vaso. Dissertação (mestrado) - Escola superior de Agricultura "Luiz de Queiroz". Piracicaba, SP. 2014. 66p.

CASTR0, C. N.. A agricultura no nordeste brasileiro: 0portunidades e limitaçoes ao desenvolvimento. Texto para Discussão. n. 1786, Instituto de Pesquisa Econômica Aplicada (IPEA), Brasília, 2012.

CORREIA, R. C.; KIILL, L. H. P.; MOURA, M. S. B. DE; CUNHA, T. J. F.; JESUS JUNIOR, L. A. DE; ARAÚJ0, J. L. P.. A região semiárida brasileira. Embrapa Semiárido, 2011. Disponível em:

https://ainfo.cnptia.embrapa.br/digital/bitstream/item/54762/1/01-A-regiaosemiarida brasileira.pdf-18-122011.pdf. Acesso em: 03/02/2018.

COSTA, I. J. S.; COSTA, B. N. S.; ASSIS, FRANSCINAMENTE APARECIDA DE, MARTINS, ADALVAN DANIEL, PIO, LEILA APARECIDA SALLES, \& PASQUAL, MOACIR. Crescimento e fisiologia da geleia (Butia capitata) cultivada sob redes de sombra coloridas. Acta Scientiarum. Agronomy, v. 40, 2018.

COSTA, L. C. B.; PINTO, J. E. B. P.; CASTRO, E. M.; ALVES, E.; BERTOLUCCI, S. K. V.; ROSAL, L. F.. Efeitos da tela colorida de sombreamento no desenvolvimento vegetativo e na estrutura foliar de 0cimum selloi. Bragantia, v.69, n.2, 2010 .

DNOCS. Limoeiro do Norte - CE. 2015. Disponível em:

http://www.dnocs.gov.br/ dnocs/doc/canais/perimetros_irrigados/ce/jaguaribe_apodi.html. Acesso em: 07/05/2017

DOUSSEAU S.; ALVARENGA, A. A.; SANTOS, M. 0.; ARANTES, L. 0.. Influência de Diferentes Condições de Sombreamento sobre o Crescimento de Tapirira guianensis Alb. Revista Brasileira de Biociências, Porto Alegre, v. 5, supl. 2, p. 477-479, 2017.

FIGUEIRED0, G.; LEITE, C.. Tipos de Estruturas Plásticas Utilizadas para Cultivo em Ambiente Protegido. Casa da agricultura, produção em ambiente protegido. Campinas, n.2, p.17-20, 2011.

HENRIQUE, P. C.; ALVES, J. D.; DEUNER, S.; GOULART, P. F. P.; LIVRAMENTO, D. E. Aspectos fisiológicos do desenvolvimento de mudas de café cultivadas sob telas de diferentes colorações. Pesquisa Agropecuária Brasileira, Brasília, v. 46, n. 5, p.458-465, 2011.

HIRATA, E. K.. Respostas fisiológicas da rúcula ao cultivo sob telas fotoconversoras no inverno e no verão. 2014. Dissertação (Mestrado em Agronomia) - Universidade do Oeste Paulista - Unoeste, São Paulo.

MAGUIRE, J. D.. Speed of germination aid in selection and evaluation for seedling emergence and vigor. Crop Science, Madison, v. 2, n. 2, p.176-77, 1962.

MALAVOLTA, E; VITTI, G.C.; OLIVEIRA, S. A.. Avaliação do estado nutricional das plantas: princípios e aplicações. Associação Brasileira para Pesquisa do Potássio e do Fosfato, Piracaba. p. 201. 1989.

MARTINAZZO, E. G.; ANESE, S.; WANDSCHEER, A. C. D.; PASTORINI, L. H.. Efeito do sombreamento sobre os Teores de Carboidratos Não-estruturais de Eugenia uniflora L. (Pitanga) - Myrtaceae. Revista Brasileira de Biociências, Porto Alegre, v. 5, supl. 2, p.168-170, 2007.

MELO JUNIOR, J. L. A.; MELO, L. D. F. A.; FERREIRA, V. M.; ARAUJ0 NET0, J. C. Germination and morphology of seeds and seedlings of Colubrina glandulosa Perkins after overcoming dormancy. Australian Journal of Crop Science, v.12, p.639-647, 2018.

NASCIMENTO, M. E.; PINT0, J. E. B. P.; SILVA JÚNIOR, J. M.; CASTRO, E. M.; SANTOS, F. M.. Plasticidade foliar e produção de biomassa seca em Copaifera langsdorffii Desf. cultivada sob diferentes espectros de luz. Revista de Ciências Agrárias: Revista Amazonion de Ciências Agrárias e Ambientais, v. 57 (1), p. 41-48, 2014.

OLIVEIRA, N. T.; NASCIMENTO, K. P.; GONÇALVES, B. 0.; LIMA, F. C.; COSTA, A. L. N.. Tratamento de água com moringa oleifera como coagulante/floculante natural. Revista Científica da Faculdade de Educação e Meio Ambiente. Ariquemes: FAEMA, v. 9, n. 1, 2018. 
RIBEIRO, A. S. Cultivo sob malhas no crescimento, desenvolvimento e composição química do óleo essencial de Patchouli. 2015. Dissertação (Mestrado em Plantas Medicinais, Aromáticas e Condimentares: área de concentração em Cultivo e Manejo Sustentável em Plantas Medicinais). Universidade Federal de Lavras (UFLA), Lavras.

ROLIM, J. C.; NOGUEIRA, M. R. S. ; LIMA, P. R. S. ; BANDEIRA, F. C. V.; PORDEUS, M. A. A.; CASTRO, A. A.; PITTA, G. B.; DINIZ, M. F. F. M.; PEREIRA, A. H.. Hiperplasia miointimal na artéria ilíaca em coelhos submetidos à angioplastia e tratados com Moringa oleifera. Rev. Col. Bras, v. 43, n. 1, p. 28-34, 2016.

SABINO, M., KORPAN, C.; FERNEDA, B. G., SILVA, A. C. Crescimento de mudas de ipês em diferentes telas de sombreamento. Nativa, Sinop, v.4, n.2, p.61-65, 2016.

SAMPAIO, P. R. F.. Malhas fotoconversoras e concentrações de potássio via fertirrigação no cultivo de Costus lasius Loes. em ambiente protegido. 2018 Tese (Doutorado em Ciências: Engenharia de sistemas agrícolas) Piracicaba, São Paulo.

SARAIVA, G. F. R.. Influência do uso de telas de sombreamento coloridas (azul, vermelha e preta) na fisiologia da produção de mudas de guanandi (Calophyllum brasiliensis). 2013. Dissertação (Mestrado em Ciências biológicas), Universidade Estadual Paulista, Botucatu-SP, Brasil.

SILVA, F.C..Manual de análises químicas de solos, plantas e fertilizantes. Embrapa Informação Tecnológica, 2009. Disponível em: http://livraria.sct.embrapa.br/liv_resumos/pdf/00083136.pdf. Acesso em: 14/02/2019

SILVA, P. C. G.; MOURA, M. S. B.; KIILL, L. H. P.; BRITO, L. T. L.; PEREIRA, L. A.; SA, I. B.; CORREIA, R. C.; TEIXEIRA, A. H. C.; CUNHA, T. J. F.; GUIMARÃES FILHO, C.. Caracterização do semiárido brasileiro: fatores naturais e humanos. In: SA, I. B.; SILVA, P. C. G.. Semiárido brasileiro: pesquisa, desenvolvimento e inovação. Petrolina: Embrapa Semiárido, 2010. cap. 1, p.18-48.

SOUZA, G. S.; SILVA, J. S.; OLIVEIRA, U. C; NETO, R. B. S.; SANTOS, A. R.. Crescimento vegetativo e produção de óleo essencial de plantas de alecrim cultivadas sob telas coloridas. Biosci. J., Uberlandia, v. 30, supplement 1, p. 232$239,2014$.

TAIZ, L;; ZEIGER, E. Fisiologia vegetal. 5 ed., Porto Alegre: Artmed, 2013. 513 p.

VIEIRA, J. S.. Propagação vegetativa, crescimento e teor de proteína em ora-pro-nóbis (Pereskia aculeata Miller) cultivado sob telas fotosseletivas. 2017. Dissertação (Mestrado em Olericultura) - Instituto Federal de Educação, Ciência e Tecnologia Goiano - Campus Morrinhos, Goiás.

YEMN, E. W.; WILLIS, A. J. The estimation of carbohydrate in plant extracts by anthrone. The Biochemical Journal, London, v. 5, p. 508-514, 1954. 